\title{
AS ALTERNATIVAS JURÍDICAS PARA UMA ÉTICA DA LIBERTAÇÃO: DO DIREITO ALTERNATIVO A UMA HERMENÊUTICA FILOSÓFICA CRÍTICA
}

\author{
Murilo Carvalho Sampaio*
}

\begin{abstract}
RESUMO
Este ensaio trata das possibilidades de atuações jurídicas comprometidas com uma ética da libertação no contexto de crise social. Inicia apresentando a proposta da ética libertadora, a partir de Enrique Dussel e Celso Ludwig, frente ao contexto de exclusão social, para, adiante, situar a crítica ao Direito e identificar as premissas de um considerado Direito Crítico, com base em Agostinho Ramalho Marques Neto. Prossegue com o debate entre o Direito Crítico e a Política a partir da contribuição de Rosa Luxemburgo, bem como trata das críticas ao direito alternativo até a emersão da hermenêutica filosófica. Elenca a potencialidade de uma hermenêutica crítica, em especial a defendida por Lênio Streck, como perspectiva jurídica de concretização de uma ética libertadora.
\end{abstract}

Palavras-chave: ética da libertação; direito alternativo; hermenêutica filosófica.

\begin{abstract}
This essay discusses the possibilities of legal actions committed to an ethic of liberation in the context of social crisis. Starts presenting the proposal of ethics liberating, from Enrique Dussel and Celso Ludwig, opposite the context of social exclusion, for, go ahead and put the criticism of the law and identify the premises of a law deemed critical, based on Agostinho Neto Marques Ramalho . It continues with the debate between the Law and Critical Policy from the contribution of Rosa Luxemburg and deals with the criticism the right alternative to the emergence of philosophical hermeneutics. Lists the potential for a critical hermeneutics, especially championed by the Lênio Streck, as a legal viewpoint of achievement for an ethics liberating.
\end{abstract}

*Juiz do Trabalho da $9^{\text {a }}$ Região, especialista em Direito do Trabalho, Mestre em Direito Privado pela UFBA, Doutorando em Direito pela UFPR, Membro do Instituto Baiano de Direito do Trabalho - IBDT. murilosampaio@yahoo.com.br. 


\section{AS Alternativas JURídicas PARA UMA ÉTICA dA LIBERTAÇÃo: DO DIREITO \\ ALTERNATIVO A UMA HERMENÊUTICA FILOSÓFICA CRÍTICA}

Key words: ethic of liberation; right alternative; philosophical hermeneutics.

SUMÁRIO: 1 INTRODUÇÃO; 2 UMA ÉTICA DA LiBERTAÇÃO; 3 DiREITO E CRÍTICA; 4 UM Direito CRítico; 5 Direito e Política; 6 A HERMENÊUTICA FILOSÓFICA; 7 UMA HERMENÊUTICA CRÍTICA; 8 (IN) CONClusÕES; 9 REFERÊNCIAS.

\section{INTRODUÇÃO}

Sustentar uma ética da libertação contemporaneamente representa a adoção de uma análise e de uma prática comprometida com a transformação social do padrão vigente de vida e da sociedade. A transformação se faz necessária frente aos cotidianos paradoxos e a crise que acomete à sociedade e, particularmente, ao direito. O sociólogo português Boaventura de Souza Santos, em lapidar expressão sintetiza este contexto: "Há um desassossego no ar. Tem-se a sensação de estar na orla do tempo, entre um presente quase a terminar e um futuro que ainda não nasceu". ${ }^{1}$ Este desassossego pode ser traduzido nos verbetes "crises, perplexidades e paradoxos" que recaem sobre a sociedade atual.

Em linguagem poética, Carlos Drummond de Andrade, há mais de cinqüenta anos, diagnosticava dizendo:

Este é tempo de partido. Tempo de homens partidos. Em vão percorremos volumes, Viajamos e nos colorimos. A hora pressentida esmigalha-se em pó na rua. Os homens pedem carne. Fogo. Sapatos. As leis não bastam. Os lírios não nascem da lei. [...] Calo-me, espero, decifro. As coisas talvez melhorem. São tão fortes as coisas. ${ }^{2}$

1 SANTOS, Boaventura de Souza. Porquê pensar? Revista da AATR - Associação de Advogados de Trabalhadores Rurais, Salvador, a. 3, n. 3, p. 41, 2005.

2 ANDRADE, Carlos Drummond. A rosa do povo. 25. ed. Rio de Janeiro: Record, 2002, p. 38. 
O tempo de partido de Drummond faz-se, ainda, tempo presente, no qual os homens estão divididos entre a crise que os consome e as esperanças que emergem ${ }^{3}$. A poesia "Nosso tempo" permanece atual, vivificado nos reclames por carne, fogo e sapatos, enquanto os direitos humanos, suas definições, suas declarações e regulamentações não bastam. Depara-se, atônita e paradoxalmente, com "as coisas" o sistema social, o Estado, a ciência, a técnica, na constante expectativa da melhoria. No entanto, as (outras) "coisas" - o Capitalismo, os interesses, a luta pelo poder e por sua manutenção, são tão fortes, que não permitem sua transformação, fazendo o homem novamente partido. Pode-se, então, identificar o contexto crítico essencialmente no caráter paradoxal da vida humana e suas possibilidades: ao mesmo tempo em que o homem desenvolve inúmeros instrumentos (ciência, direito e trabalho) que propiciam, além da sua autonomia perante a natureza, incontáveis possibilidades de uma vida digna, enfrentam-se, por outro lado, problemas persistentes que assolam todos os segmentos sociais, gerando medo, insegurança, violência, guerras e incertezas.

O paradoxo do momento atual é patente! No tocante ao Estado, a conjunção global que cria fluxos supranacionais e, supostamente, uma maior interação mundial, termina, ao ser dirigida pelo neoliberalismo, produzindo exclusão e distanciamento. No mundo do trabalho, a automação e os novos processos se instalam sugerindo um trabalho com menos fadiga e mais criativo, contudo tem se mostrado um labor que suga, não mais somente o suor do trabalhador, mas extrai a própria consciência nas visíveis medidas de cooptação rotuladas de interação capital-trabalho; na ciência, a consciência, antes apta a identificar a verdade com exclusividade resgata a linguagem e a filosofia, embora os consensos argumentativos não possam ser verdades para aqueles que não tem o direito à fala, porque se alienam no trabalho ou estão excluídos de espaços de participação. No direito, a defesa da legalidade-constitucionalidade, no

\footnotetext{
${ }^{3}$ OLIVEIRA, Murilo Carvalho Sampaio Oliveira. Crise do direito do trabalho. Revista LTR, v. 70 , p. $998,2006$.
} 


\section{AS Alternativas JURídicas PARA UMA ÉTICA dA LIBERTAÇÃo: DO DIREITO \\ ALTERNATIVO A UMA HERMENÊUTICA FILOSÓFICA CRÍTICA}

intento de conter a ofensiva privatista, torna-se progressista, quando outrora era conservadora. Destarte, a era contemporânea é demarcada por um cenário de transição paradigmática entre a modernidade e o surgimento de novos parâmetros de racionalidade e pode ser representada pela idéia de crise.

Este ensaio propõe-se a situar, a grosso modo, as possibilidades de atuações jurídicas comprometidas com uma ética da libertação perante a crise social. Nestes termos, o texto delineia a proposta da ética libertadora frente ao contexto de exclusão social, para, então, proceder uma crítica ao Direito e identificar as premissas de um considerado Direito Crítico. Adiante, enfrenta o debate entre o Direito Crítico e a Política, bem como trata das críticas ao direito alternativo até a emersão da hermenêutica filosófica. Pontua a potencialidade de uma hermenêutica crítica como perspectiva jurídica de concretização de uma ética libertadora.

\section{UMA ÉTICA DA LIBERTAÇÃO}

Na sociedade global, é premente a necessidade de uma ética libertadora capaz de responder ao quadro de exclusão, concentração de renda, violência e ausência de esperanças. Enrique Dussel estabelece a diretriz dessa ética:

[...] uma ética de afirmação total da vida humana ante o assassinato e o suicídio coletivo para os quais a humanidade se encaminha se não mudar o rumo do seu agir irracional. A Ética da libertação pretende pensar filosófico-racionalmente esta situação real e concreta, ética, da maioria da humanidade presente, próxima de um conflito trágico de proporções nunca vistas na história da espécie humana ${ }^{4}$.

${ }^{4}$ DUSSEL, Enrique. Ética da libertação na idade da globalização e da exclusão. Trad. Ephraim Ferreira Alves, Jaime A Clasen, Lúcia M.E. Orth. Petrópolis: Vozes, 2007, p. 11. 
Os dados da Organização das Nações Unidas ${ }^{5}$ são estarrecedores, porquanto confirmam, com a matemática da vida, o momento de exclusão e pobreza contemporâneo. Um bilhão de pessoas no mundo vivem em estado de extrema pobreza, possuindo menos de um dólar por dia, o que corresponde a aproximadamente 1/5 da população global. Calcula-se que existam 59 milhões de crianças famintas nos países em desenvolvimento, sendo que 23 milhões vivem na África. Com a invasão do Iraque pelos Estados Unidos da América em 2003 e o atual estado de violência, 151 mil iraquianos já foram mortos. Cerca de 50 milhões de pessoas deverão se tornar "refugiados" até 2010 devido à degradação do meio ambiente, constata um estudo realizado pelo Instituto Universitário das Nações Unidas para o Meio Ambiente e Segurança Humana. Diante dos seus números, a ONU declara:

A pobreza raramente é acidental. Tal como é entendida hoje, é mais fruto de opções políticas do que qualquer outra coisa. As políticas públicas, em nível nacional e internacional, ignoram muitas vezes ou violam flagrantemente os critérios essenciais de redução da pobreza, incluindo os direitos humanos ${ }^{6}$.

No Brasil não há tanta diferença. Embora se tenha um quadro econômico estável e com crescimento razoável, a marca maior do Estado brasileiro é a gritante desigualdade e concentração de renda, o que permite até denominar a questão de apartheid social. Segundo Márcio Pochmann ${ }^{7}$, somente 5 mil dentro do total de 51 milhões de famílias detém $40 \%$ da renda nacional. Quando se amplia o leque destes 5 mil super-ricos para os $10 \%$ da população mais afortunados, verifica-se que este décimo detém $75 \%$ da riqueza nacional, ou seja, $90 \%$ da população brasileira sobrevive com os $25 \%$ remanescentes da renda. O número total de miseráveis ${ }^{8}$ no

${ }^{5}$ ONU in <http://www.un.org > Acesso em: 26 fev. 2008.

${ }^{6}$ Ibidem.

7 POCHMANN, Márcio. Razões da desigualdade no Brasil. In: <http://www.vermelho.org.br/diario/2005/1002/1002_pochmann.asp> Acesso em: 27 fev. 2008.

8 IPEA. Previdência reduziu em 44\% o número de miseráveis, diz Ipea. In: <http://www.ipea.gov.br/003/00301009.jsp?ttCD_CHAVE=2498> Acesso em: 27 fev. 2008. 


\section{AS ALTERNATIVAS JURÍDICAS PARA UMA ÉTICA DA LIBERTAÇÃO: DO DIREITO \\ ALTERNATIVO A UMA HERMENÊUTICA FILOSÓFICA CRÍTICA}

Brasil corresponde a 21,7 milhões em 2006. Seria de R \$38,9 milhões caso 17,2 milhões não fossem beneficiários dos programas assistenciais governamentais.

Para agravar a situação o discurso neoliberal apresenta-se como única possibilidade política-econômica, embora o Estado do Bem-Estar Social ainda não tenha sequer se consolidado e ofertado um mínimo de direitos às maiorias e aos excluídos. Lênio Streck revela o paradoxo dessa fórmula de diminuição do Estado:

[...] em nosso país as promessas da modernidade ainda não se realizaram. E, já que tais promessas não se realizaram, a solução que o establishment apresenta, por paradoxal que possa parecer, é o retorno ao Estado (neo)liberal. Daí porque a pós-modernidade é vista como a visão neoliberal. Só que existe um imenso déficit social em nosso país, e, por isso, temos que defender as instituições da modernidade contra esse neoliberalismo pós-moderno ${ }^{9}$.

Disto se faz necessário um urgente compromisso de luta pela emancipação dos excluídos, especialmente em defesa e efetivação dos direitos humanos. Para Marx e Engels $^{10}$, a emancipação significa a capacidade de autoconsciência, que transforma o homem em sujeito e não em objeto da história. Com a superação da alienação, os sujeitos emancipados podem construir uma nova forma de sociedade, sem a exploração do homem pelo homem, o que possibilita ser agente e não objeto da realidade. Urge, assim, uma razão libertadora (e crítica) que se realize pela via da razão estratégica-crítica (ação). A razão estratégica, enquanto proposta de ação, guiase pelo fim almejado, porém, pela qualidade crítica (libertação que contém) deve envolver a participação das vítimas. É essa a opinião de Enrique Dussel:

A razão estratégica-crítica em seu exercício último ou concreto realiza uma ação transformadora, partindo dos princípios críticos da razão prático-material e discursivoformal, das teorias científicas críticas, dos projetos alternativos formulados, do uso da razão instrumental técnico-crítica, na realidade empírica, tendo em conta os "diagramas" das

9 STRECK, Lênio. Hermenêutica jurídica $e(m)$ crise: uma exploração hermenêutica da construção do direito. 6. ed. Porto Alegre: Livraria do Advogado, 2005, p. 26-27.

${ }^{10}$ MARX, Karl; ENGELS, Friedrich. Ideologia alemã. São Paulo: Martins Fontes, 1998. 
relações de poder [...], incluindo também a macrofísica do poder ${ }^{11}$.

No contexto de apartheid social, o Direito termina por reforçar a exclusão, porque fora concebido para o sujeito mediano - normalmente o proprietáriocontratante com seus iguais, bem distinto da grande maioria dos sujeitos reais que vivem em ausência dos direitos fundamentais. A perspectiva positivista-normativista conjugada com a cultura formalista resulta na dificuldade tanto de acesso como de obtenção e, por consequiência, de efetivação dos direitos destes excluídos. Lênio Streck visualiza um fosso entre o Direito e a sociedade, decorrente da "incapacidade histórica da dogmática jurídica (discurso oficial do Direito) em lidar com a realidade social" ${ }^{12}$.

Frente a esse quadro, é preciso transformar os moldes da atual sociedade para constituir um olhar em favor das maiorias excluídas e oprimidas, ou seja, buscar uma ética da libertação. Nesta perspectiva, o direito também se afigura como espaço de transformação mesmo com sua ontologia conservadora.

A negação da opressão inicia-se e é possível pela afirmação da exterioridade do outro (aqui o pobre e oprimido nunca inteiramente subsumido em qualquer dos níveis de dominação). Dessa maneira, o pobre/oprimido merece justiça em razão da dimensão constitutiva do seu ser como exterioridade, em fundamentação ética-metafísica ${ }^{13}$.

Assim, é possível pontuar propostas para o direito a partir do viés da ética da libertação. Impõe-se, então, cogitar o espectro da ética da libertação na seara jurídica.

${ }^{11}$ DUSSEL, op. cit., p. 506.

${ }^{12}$ STRECK, op. cit., p. 17.

${ }^{13}$ LUDWIG, Celso. Para uma filosofia jurídica da libertação: paradigmas da filosofia da libertação e direito alternativo. Florianópolis: Conceito, 2006, p. 216. 


\section{AS Alternativas JURídicas PARA UMA ÉTICA dA LIBERTAÇÃo: DO DIREITO \\ ALTERNATIVO A UMA HERMENÊUTICA FILOSÓFICA CRÍTICA}

\section{DIREITO E CRÍTICA}

Mesmo com muitas desconfianças e dúvidas, pode-se apontar um viés de contribuição do Direito, ainda que limitado, para transformação deste cenário de exclusão e perplexidade. Trata-se de perfazer a crítica a direito praticado e a proposição de outras possibilidades de atuação jurídica. A tarefa da crítica jurídica imprescinde da compreensão da chamada Teoria Crítica enquanto análise epistemológica dialética:

A Teoria Crítica expressa a idéia de razão vinculada ao processo histórico-social e à superação de uma realidade em constante transformação. Epistemologicamente, a Teoria Crítica surge como uma 'teoria' mais dinâmica e abrangente, superando os limites naturais das teorias tradicionais, pois não se atém a descrever o estabelecido ou contemplar equidistantemente os fenômenos reais. Seus pressupostos de racionalidade são 'críticos' na medida em que articula, dialeticamente, a 'teoria' com a 'práxis', o pensamento crítico revolucionário com a ação estratégica ${ }^{14}$.

A teoria crítica fornece o esteio para um repensar crítico do Direito, notadamente nas correntes jusfilosóficas: o antigo Jusnaturalismo e o Positivismo Jurídico em declínio. As concepções tradicionais do Direito podem ser resumidamente agrupadas em correntes idealistas e empiristas ${ }^{15}$. As idealistas englobam o Jusnaturalismo proposto pelo idealismo kantiano, o idealismo hegeliano e o idealismo jurídico contemporâneo (Stammler, Radbruch, Recaséns Siches, Del Vecchio), enquanto as empiristas seriam representados pela Escola da Exegese (Bugnet e Austin), Escola Histórica (Savigny e Puchta), a Escola Sociológica (Duguit, Pontes de Miranda), Dogmatismo Normativista (Positivismo Jurídico) de Kelsen e o Egologismo Existencial de Cossio (Machado Neto).

É imperativo situar histórica e socialmente estas concepções acerca do Direito.

14 WOLKMER, Antônio Carlos. Introdução ao pensamento jurídico crítico. São Paulo: Acadêmica, 2000, p. 16-17.

${ }^{15}$ MARQUES NETO, Agostinho Ramalho. A ciência do direito: conceito, objeto e método. São Paulo: Forense, 2000. 
Particularmente, faz-se necessário compreender estes modelos de ideologia jurídica como resultantes da modernidade e do modo de produção capitalista:

A cultura jurídica produzida ao longo dos séculos XVII e XVIII, na Europa Ocidental, resultou de um específico complexo de condições engendradas pela formação social burguesa, pelo desenvolvimento econômico capitalista, pela justificação do interesse liberalindividualista e por uma estrutura estatal centralizada. Certamente que este entendimento não só compartilha da idéia de que subsiste em cada período histórico uma prática jurídica dominante, como sobretudo, confirma a concepção de que o Direito é sempre produto da vida organizada enquanto manifestação de relações sociais provenientes das necessidades humanas $^{16}$.

Nesse sentido, Machado Neto ${ }^{17}$ contextualiza, historicamente, as ideologias jurídicas. "Se o jusnaturalismo racionalista foi expressão do mundo burguês ascendente, o historicismo a expressão da contra-revolução, o legalismo exegético e positivismo sociológico as ideologias do mundo burguês dominante."

Portanto, a negação do Positivismo Jurídico e do Jusnaturalismo é fundante para a construção de uma crítica ao Direito, que esteja em consonância com os anseios dos sujeitos sociais no momento histórico atual. Estas duas ideologias jurídicas representam, simbolicamente, o projeto de Ciência Jurídica da modernidade. O Jusnaturalismo serviu, basicamente, à implantação dos valores político-sociais da burguesia num período de transição do Feudalismo para o Capitalismo, enquanto o Positivismo propõe-se à conservação do status quo, ao defender a incontestável imperatividade da norma jurídica e da legalidade. Assim, uma visão crítica do Direito precisa romper com estas ideologias jurídicas, que, intrinsecamente, servem ao Projeto da Burguesia e ao Capitalismo.

O Jusnaturalismo consiste numa concepção idealista do Direito, fundamentando-se num "Direito Natural" do homem. São características do Jusnaturalismo a imutabilidade, a universalidade e o ideal abstrato de justiça. O

${ }^{16}$ WOLKMER, op. cit., p. 1.

${ }^{17}$ MACHADO NETO, A. L. Compêndio de introdução à ciência do direito. 6. ed. São Paulo: Saraiva, 1988, p. 47. 


\section{As ALTERNATIVAS JURÍDICAS PARA UMA ÉTICA DA LIBERTAÇão: DO DIREITO \\ ALTERNATIVO A UMA HERMENÊUTICA FILOSÓFICA CRÍTICA}

Direito Natural tem origem, abstratamente, na natureza das coisas, isto é, na natureza do cosmo, na natureza de Deus e na natureza do homem.

A pretensão universal e abstrata desta ideologia jurídica é característica inerente à cultura jurídica da modernidade. São pressupostos do Direito Moderno o individualismo, o liberalismo e a abstração (distanciamento) das reais condições sociais. Ou seja, o Direito Natural, apesar de ser propalado como pertencente a todo homem, não se propõe a enfrentar as desigualdades referentes à coletividade, pelo contrário, apenas assenta-se na defesa do ideal de justiça do indivíduo isoladamente (mais exatamente do indivíduo burguês).

Deve-se compreender, diferentemente do propugnado pelo Jusnaturalismo, que todo o Direito é particular e concreto, uma vez que o Direito só realiza-se na situação concreta e real. Da mesma forma, não se pode acreditar que o Direito represente a vontade geral da sociedade, mas que seja resultante dos interesses dos grupos sociais hegemônicos. A suposta universalidade do Direito Natural é descaracterizada pelos condicionamentos histórico-sociais e pelo grupo social que se utiliza dessa ideologia jurídica. Desta forma, percebe-se seu caráter ideológico (ilusório e falseador) por tentar omitir sua espaço-temporalidade e o real interesse a que se propõe, através de uma propaganda universalista e abstrata. Portanto, a concepção jusnaturalista não é capaz de corresponder ao atual momento históricosocial, tampouco pode fundamentar filosoficamente uma ruptura histórica.

De outro lado, o Positivismo Jurídico constitui-se como principal ideologia jurídica contemporânea, embora em flagrante declínio com a ascensão do discurso do pós-positivismo principiológico. A pretensão maior do Positivismo Jurídico é a separação e definição do objeto da ciência do Direito. Para tanto, concebeu, ao expurgar a metafísica, a axiologia, filosofia, sociologia, história, economia, entre outros conhecimentos, um objeto preciso e neutro para o Direito: a norma.

Percebe-se uma característica fulcral do Positivismo, o formalismo jurídico. A validade da norma, pela ótica positivista, não reside na legitimidade ou na consonância com os anseios da sociedade, mas na coerência interna da norma com o sistema 
jurídico, principalmente em relação à norma hipotética fundamental. Isto é independentemente do seu conteúdo, o respeito ao processo legislativo e a concatenação com o ordenamento jurídico por si só asseguram validade à norma.

É justamente neste momento que esta ideologia jurídica, pretendendo ser neutra e imparcial, pode transforma-se em excessivamente parcial e dirigida, em razão da não observância da legitimidade do conteúdo da norma. O critério da devida formalidade é, notadamente, insuficiente para garantir a desejada neutralidade. Ocorrendo exatamente o contrário, pois o desprestígio do substrato sócio-político da norma pode significar uma prescrição legalmente perfeita, contudo materialmente dirigida a favorecer um segmento ou, como normalmente ocorre, destinada à manutenção da ordem social vigente.

O caráter mecanicista da interpretação positivista associado a uma postura supostamente anti-ideológica ocasiona o contrário do pretendido, ou seja, termina servindo a sistemas políticos jurídicos bem diversos, compreendendo desde democracias até as mais fascistas ditaduras. Isto se deve à concepção do Direito como mera técnica da norma, em outras palavras, como simplesmente instrumento de regulação-conservação social. Portanto, é preciso romper com o formalismo jurídico que impõe o primado dos aspectos formais em detrimento do conteúdo da norma. $\mathrm{O}$ Direito não pode ser apenas normatividade posta, como prescreve o Positivismo.

\section{UM DIREITO CRÍTICO}

Tanto o Jusnaturalismo, como o Positivismo revelaram-se, por meio dessa análise dialética, imbuídos dos interesses de um grupo social - a burguesia, que pretendia e conseguiu fazer-se hegemônico. Para assegurar sua dominação política e ideológica, estas ideologias promoveram uma transmutação de seus interesses particulares em interesses gerais da sociedade, a partir da tentativa de considerar o Direito, no plano teórico, sempre abstrato e universal. Entretanto, a realidade social e a 


\section{AS Alternativas JURídicas PARA UMA ÉTICA dA LIBERTAÇÃo: DO DIREITO \\ ALTERNATIVO A UMA HERMENÊUTICA FILOSÓFICA CRÍTICA}

eficácia/efetividade do Direito no mundo excludente demonstram com força seu caráter particularista, ao produzir situações de absurda desigualdade e a própria negativa dos direitos postos fundamentais para as populações oprimidas, notadamente, as populações excluídas da sociedade (mendigos, moradores de rua, entre outros). Então, a noção de Direito representa, em grande medida, interesses de classe ou grupo social.

O compromisso acima de libertação exige, pois, uma re-orientação dos destinatários da aplicação do direito. A concepção crítica jurídica dirige-se para outros grupos sociais: as classes ou setores sociais oprimidos tanto pelo modo de produção capitalista, como pela relação de opressão da própria estrutura da sociedade (expressas pelas categoriais de gênero, etnia, sexualidade, entre outros). Vislumbra-se, assim, uma ampliação do conceito marxiano de classe trabalhadora, com a agregação de outros sujeitos sociais em situação de opressão e, mais recentemente, em situação de exclusão social, do qual se pode ser ressignificado a expressão "povo", como alude Celso Ludwig:

O povo também é classe, porém nem sempre. Há os excluídos das classes. Nos países (periféricos notadamente) em que o capital subsume apenas pequena parte do povo à categoria de "classe", esta não abarca todos os excluídos (este é o nível mais abstrato da exclusão) e dominados. Assim, "povo" por ser categoria sintética, inclui a de "classe" e, portanto, não a nega ${ }^{18}$.

Por outro lado, o fenômeno jurídico deve ser compreendido na contextualidade histórica de uma determinada sociedade. Um direito considerado crítico é um direito histórico, encarado como resultante da processualidade histórica. Por consequiência, deverá estar consciente da sua inconclusão e constante transformação, da mesma forma como ocorre com a sociedade. A vida humana em sociedade é marcada pela constante transformação, sempre engendrando novas realidades e, conseqüientemente, novos direitos.

\footnotetext{
${ }^{18}$ LUDWIG, op. cit., p. 213.
} 
Revista Eletrônica do CEJUR, Curitiba-PR, a. 2, v. 1, n. 3, ago./dez. 2008

A inconclusão e o inacabamento são características que permitem a um Direito crítico obter maior consonância com a realidade concreta, e por isso, satisfazer mais adequadamente os interesses sociais. É na própria contradição histórica que o Direito encontra os fundamentos para sua reconstrução e seu refazimento, de acordo com as novas circunstâncias da espaço-temporalidade em que se encontra.

Lyra Filho sintetiza:

Direito é processo, dentro do processo histórico: não é coisa feita, perfeita e acabada: é aquele vir-a-ser que se enriquece nos movimentos de libertação das classes e grupos ascendentes e que definha nas explorações e opressões que o contradizem, mas de cujas próprias contradições brotarão as novas conquistas ${ }^{19}$.

Esta visão atribui ao direito um caráter instrumental. Desta maneira, Lyra Filho defende o uso das contradições do sistema jurídico em favor da libertação e da criação dentro da "pluralidade de ordenamentos" de novos instrumentos jurídicos de ação. Ressalta, ainda, que não se pretende apenas uma atitude crítica prática, mas uma verdadeira reconstrução do Direito, como modelo teórico e proposta de ação, tornado instrumento de emancipação. Na aplicação do Direito, Souza Junior contribui para a delimitação de uma concepção crítica do Direito:

\begin{abstract}
Note-se que, no contexto, as normas estatais representam apenas uma e incidente do processo jurídico. O Direito completo está na dialética da dominação-libertação; busca uma ordem eficaz e justa; emaranha-se e se desnatura nos interesses estabelecidos; e recupera fôlego, para determinar os reordenamentos superiores mais avançados. As visões mesmas da justiça estão obviamente condicionadas pelo posicionamento das classes e dos grupos; e medem-se, em eficácia e legitimidade, pela sua ligação com o movimento progressista e ascendente - apesar de todas as contradições e mediações, que dele não fazem uma linha reta; antes, compõem o processo em espiral ${ }^{20}$.
\end{abstract}

Nesse sentido, sustenta-se que a eficácia/efetividade das normas deve se

${ }^{19}$ LYRA FILHO, Roberto. O que é direito. Rio de Janeiro: Brasiliense, 1982, p. 86.

${ }^{20}$ SOUZA JR, José Geraldo. Para uma crítica da eficácia do direito. Porto Alegre: Fabris, 1984, p. 121. 


\section{AS Alternativas JURídicas PARA UMA ÉTICA dA LIBERTAÇÃo: DO DIREITO \\ ALTERNATIVO A UMA HERMENÊUTICA FILOSÓFICA CRÍTICA}

relacionar à legitimidade do seu conteúdo prescritivo perante os interesses e necessidades dos seus destinatários supra-indicados. Ou seja, concebendo criticamente o Direito, a validade e aplicação das normas estariam vinculadas à noção de justiça do seu conteúdo diante da realidade social concreta, na qual produziria efeitos. Exige-se uma consonância entre a norma e sua legitimidade. Nesse pensamento, a construção hermenêutica-crítica coloca-se a favor de outro ideal de Justiça. O movimento de Direito Alternativo corresponde a esta alusão, que promove interpretações em favor da Justiça social dentro do ordenamento jurídico. Celso Ludwig anota que esta guinada hermenêutica tem como base a Teoria Crítica:

No Brasil, os chamados alternativismos históricos, desde o "direito achado na rua" até o movimento do "direito alternativo", revelam no fundo uma implicação política-jurídica dos postulados da Teoria Crítica do Direito, e para ela convergem, quando necessitam de um modelo epistêmico e axiológico alternativo em relação à dogmática tradicional ${ }^{21}$.

Este Direito Crítico promove a ruptura com o "sono dogmático" que acomete os juristas tradicionais, ora no Jusnaturalismo, ora no Positivismo. Esta concepção é aqui delineada por quatro vetores: finalidade; construção científica; aplicação; e definição.

A finalidade deste Direito importa em afirmar que lhe compete estabelecer uma correspondência/correlação entre sua definição e as necessidades e interesses do sujeitos sociais oprimidos. Dessa forma, o Direito Crítico faz-se histórico e ideológico, posto que assume com transparência seus destinatários, sendo ciente da sua inconclusão e da constante transformação da realidade.

Na sua tradução científica, o Direito Crítico constrói seu objeto a partir da relação entre seu sistema teórico e a realidade concreta, transformando o fato social em fato jurídico. Entretanto, seu objeto não se restringe ao fato. São acrescidos o valor e a norma - componentes desta proposta de Ciência do Direito. Em busca de uma leitura

\footnotetext{
${ }^{21}$ LUDWIG, op. cit., p. 205.
} 
mais próxima da realidade, necessita da contribuição de outros saberes, e numa perspectiva interdisciplinar, aliada a uma pluralidade metodológica.

O Direito Crítico prossegue para a análise de sua aplicação, pois não poderia se limitar a construções teóricas. É, justamente, na sua aplicação que esta noção de Direito revela-se instrumental, o que, hodiernamente, tem servido à dominação e ao jugo do poder das elites. Faz-se necessário recompô-lo para que sua instrumentalidade venha a servir a outros destinatários, transmutando o Direito para espaço de liberdade e Justiça. É o compromisso da aplicação do Direito com a Justiça dos oprimidos e a sujeição da legalidade à legitimidade social que confere ao Direito sua natureza crítica.

Tornar-se necessário, então, "fazer uso do ordenamento jurídico vigente para propiciar uma prática judicial voltada aos menos favorecidos socialmente, utilizar o direito e seus instrumentos jurídicos alternativamente à prática dominante"22.

Portanto, Direito Crítico significa a compreensão do Direito em favor dos sujeitos sociais em situação de opressão, considerados em uma determinada espaçotemporalidade e, por consequiência, ciente da sua inconclusão e constante transformação, assumindo-se compromissário da concretização da Justiça Social, enquanto garantia de manifestação da liberdade e criatividade humana. O Direito Crítico é insurgente, contestador, achado na rua, alternativo e pluralista, integrado pela pretensão de emancipação social:

A práxis jurídica alternativa (Direito Alternativo em sentido amplo) configura espaço de luta motivado pela injustiça histórica real, a partir de uma antropologia ética (tendo na exterioridade a categoria fonte, abstrata em geral), e não como opção de um discurso e práticas "amigas", paternalistas e assistencialistas, ou de sentimentos de mera comiseração" 23 .

Salienta-se que a realidade social desconstrói as pretensões de coerência e completude das tradições jurídicas, pois a produção da norma nem sempre se encontra

\footnotetext{
${ }^{22}$ Ibidem, p. 189.

${ }^{23}$ Ibidem, p. 217.
} 


\section{AS Alternativas JURídicas PARA UMA ÉTICA dA LIBERTAÇÃo: DO DIREITO \\ ALTERNATIVO A UMA HERMENÊUTICA FILOSÓFICA CRÍTICA}

de acordo com o ordenamento jurídico. Destarte, a produção legislativa representa a força política dos grupos, segmentos e atores sociais na positivação dos seus interesses. Nesse sentido, as contradições e lacunas do sistema jurídico são tão latentes que permitem a existência de movimentos de crítica interna ao Direito Positivo, tais como o "uso alternativo" do Direito na Itália, Direito Alternativo e Positivismo de Combate no Brasil, entre outros que militam sob a égide do ordenamento jurídico através de processos hermenêuticos.

\section{DIREITO E POLÍTICA}

Verificada a perspectiva emancipatória do direito crítico, tornar-se necessário percorrer, ainda que rapidamente, as possibilidades e os limites da concepção da instância jurídica como instrumento de emancipação. Cuida-se de lidar com as relações entre o direito e a política, cuja aproximação é tal ao ponto de tornar-se demasiadamente frágil sua distinção. A relação entre Direito e Poder se dá em três aspectos: dominação ideológica, domestificação e linguagem. Destaca-se a linguagem enquanto forma de poder e dominação na seara jurídica justifica-se em razão das poucas reflexões sobre a questão no pensamento tradicional.

No primeiro momento, natureza ideológica transpõe também o Direito para situação de saber instrumental a serviço da dominação política. A construção da ideologia jurídica hegemônica decorre dos interesses da classe ou grupo que possui o poder político. Neste sentido, Roberto Aguiar ${ }^{24}$ vem afirmar "que o grupo que tiver o poder real, numa sociedade, deterá, como conseqüência, seu poder formal". Assim, o Direito é, em grande essência, instrumento de dominação política dos grupos hegemônicos sobre a sociedade.

No segundo aspecto, o Direito revela-se como poder disciplinar, objetivando a

\footnotetext{
${ }^{24}$ LYRA FILHO, Roberto. Para um direito sem dogmas. Porto Alegre: Fabris, 1984, p. 61.
} 
domestificação social para a assegurar o status quo, isto é, a conformação e aceitação pelos indivíduos do sistema organizativo e político como natural e justo. Promove-se desde a infância uma disciplina de respeito à ordem, introjetando a aceitação das formas de opressão social como inerentes e normais ao sistema. Para Roberto Aguiar ${ }^{25}$ "disciplinar também significa determinar posições e de pertinência ou não-pertinência. Significa honrar ou sancionar, ajustar ou estigmatiza, elevar ou destruir". Prossegue o filósofo mencionado exemplificando o caráter domestificador do Direito: "O poder em seu aparato normativo e repressivo tem meios para, através de várias vias, implementar a aceitação de seus desígnios. Ele, sutilmente, integra ou marginaliza, faz de cada homem que se encontre sob seu domínio um integrado ou um marginal". ${ }^{26}$ Assim, além da dominação política-ideológica, o Direito, mediante seu disciplinamento, atinge subjetivamente o indivíduo promovendo sua "domestificação" para a sua convivência, na verdade conformação, com a ordem social.

Nestes termos, o caminho ordinário do Direito é servir à conservação. Apesar do direito hegemônico praticado, ensinado dogmaticamente e dito servir como meio de conservação social (técnica de regulação social), tem-se o contra-direito, o Direito Crítico, insurgente, de combate, surrealista, ou qualquer outra denominação que expresse movimentos, no âmbito do direito de reação à dominação daquele direito posto e hegemônico, na direção compromisso libertário.

Para ilustrar historicamente as possibilidades emancipatórias da atuação jurídica, é oportuno formular um paralelo desta questão com o debate entre Rosa Luxemburgo e Eduard Bernstein sobre Reforma e Revolução. Resguardadas as diferenças entre as questões comparadas, pode-se aproximar o papel da ação institucional parlamentar, defendida por revolucionários e reformistas, com a utilização crítica do direito para os fins da transformação-revolução. Contudo, o elemento diferenciador entre reformismo e o viés revolucionário é a compreensão deste último que a transformação não decorrerá da ação institucional, embora esta

\footnotetext{
${ }^{25}$ Ibidem, p. 68.

${ }^{26}$ Ibidem, loc. cit.
} 


\section{AS Alternativas JURídicas PARA UMA ÉTICA dA LIBERTAÇÃo: DO DIREITO \\ ALTERNATIVO A UMA HERMENÊUTICA FILOSÓFICA CRÍTICA}

atuação detenha importância tática.

Convém situar a polêmica Bernstein e Luxemburgo para sua melhor apreensão. Conhecida como Die Rotte Rose - rosa vermelha -, Luxemburgo foi um exemplo de pessoa de superações, eis que enfrentou, já no início do século XX, todas discriminações decorrentes das condições de mulher, intelectual, judia, polonesa e deficiente física. Após seu doutoramento em Zurich, integrou como militante a cúpula do Partido Socialista Alemão juntamente com seu rival.

Já Eduardo Bernstein ${ }^{27}$, eminente teórico do partido, propunha uma revisão completa do marxismo, na qual defendia a transformação do capitalismo sem recorrer a um processo de ruptura revolucionária. Para ele, era evidente que o progresso material do final do século XIX indicava que não haveria derrubada nenhuma do capitalismo, e que estava muito longe de dar-se a tal catástrofe do sistema burguês prevista por Marx anos atrás. Cabia, então, aos socialistas e sindicatos uma postura ética de obter novas conquistas e melhoras dentro do sistema capitalista, abdicando da proposta revolucionária socialista e priorizando a ação eleitoral parlamentar. Enrique Dussel sintetiza o ideário reformista

Reformista é aquele que, pretendendo cumprir com os princípios revolucionários, caiu na adaptabilidade do capitalismo. Traduzindo na metalinguagem ética, o reformista é aquele que atua segundo critérios (isto é adaptar-se) do sistema foral hegemônico ou dominante ${ }^{28}$.

A resposta de Rosa foi dura e incisiva, e por isso tão conhecida. Atacou Bernstein de capitular à social-democracia, numa conduta clara de oportunismo. A tendência conformista também provinha da defesa da maquina partidária - 1 milhão de filiados, 3.500 empregados, 110 deputados (35\% do eleitorado), jornais, revistas e até uma universidade - que poderia ser confiscada ou arrasada a partir das primeiras ações

${ }^{27}$ REALE, Giovanni; ANTISERI, Dario. História da filosofia: de Nietzsche à Escola de Frankfurt. Trad. Ivo Storniolo. São Paulo: Paulus, 2006, p. 459.

${ }^{28}$ DUSSEL, op. cit.,p. 536. 
revolucionárias. A conseqüência do reformismo para Rosa produziria uma política de compensações e de composição de classes que resultou em medidas reformistas, mas garantidoras da ordem capitalista. Dussel assevera:

A luta contra o reformismo - que não é contra o capitalismo mas contra aqueles que, tendo sido críticos e pretendem ainda o ser, abandonaram a sua solidariedade teórica e prática com a comunidade de vítimas, embora digam o contrário - é ética, teórica e estratégica ${ }^{29}$.

Defendia a Die Rotte Rose que a transformação não decorria da luta institucional. Todavia, esta luta tem grande importância no sentido de produzir práticas no campo da institucionalidade de conscientização e acúmulo político-social para realizar a revolução. "A grande importância da luta sindical e da luta política reside em que elas socializam o conhecimento, a consciência do proletariado, organizam-no como classe" ${ }^{30}$.

Enrique Dussel distingue reformistas dos funcionais, eis os primeiros mesmo agindo dentro do parâmetro do sistema formal, afirmam o discurso crítico, enquanto que os funcionais não assumem este discurso e defende o próprio sistema formal. Dussel assevera que Rosa Luxemburgo dedicou-se com intensidade à teoria com a finalidade de combater teoricamente o discurso reformista. Nisto elaborou uma pesquisa científica, na seara de uma ciência social crítica, visando afirmar a criticidade de Marx e destruturar o discurso reformista ${ }^{31}$. Para tanto, corrigir erros sobre a interpretação reformista sobre Marx que considerava os exemplos destes como modelos rígidos e necessários, e porque não concretizados, seriam para o reformismo inválidos.

A par da historicidade, o reformismo converte-se na socialdemocracia que é capitalista, mas com um discurso crítico-social, como já anuciara Luxemburgo. Para

${ }^{29}$ Ibidem, p. 538.

${ }^{30}$ LUXEMBURGO, Rosa. Reforma ou revolução. Trad. Livio Xavier. São Paulo: Expressão Popular, 1999, p. 60.

${ }^{31}$ DUSSEL, op. cit., p. 537. 


\section{As ALTERNATIVAS JURÍDICAS PARA UMA ÉTICA DA LIBERTAÇão: DO DIREITO \\ ALTERNATIVO A UMA HERMENÊUTICA FILOSÓFICA CRÍTICA}

uma ética da libertação, o momento da crítica e ação estratégica não ocorre somente nos períodos revolucionários, os quais foram historicamente bem pontuais e descontínuos. "Assim, a revolução não é senão o momento extremo de um nível de complexidade que começa em sua posição mínima pela transformação de uma máxima da vida cotidiana em referencia à uma ação possível"32.

Deste modo, uma ética da libertação empreende uma prática de transformação social de pequenas e cotidianas ações estratégicas, que implementando uma razão crítica transformam pequenas circunstâncias e acumulam para uma transformação maior e global, inclusive sob a perspectiva dialética de que as alterações quantitativas, em determinado momento, produzem uma modificação qualitativa.

Dussel critica Luxemburgo porque esta não foge da dicotomia reformarevolução, mesmo construindo os traços de uma ética transformadora cotidiana. Uma ética transformadora cotidiana não é reformista, nem revolucionário no sentido clássico, mas uma revolução em processo, diária, dispersa e fragmentada ${ }^{33}$. Trata-se da concretização da XI tese sobre Feuerbach: "Os filósofos só interpretaram o mundo de diferentes maneiras; do que se trata é de transformá-lo" ${ }^{34}$.

Enrique Dussel vale-se do debate reforma-revolução para construir a categoria transformação social. Esta concepção de transformação social permite uma negação do desalento contemporâneo decorrente de uma vida que não tem apontando alternativas. "Não podemos aceitar o "sujeito moderno", mas também não a irracionalidade suicida de negar os princípio (a bússola) e a consciência crítica" ${ }^{35}$. "Essas transformações produzem em seu conjunto o momento do desenvolvimento que acrescenta um novo ao mero processo de produção e reprodução da vida de todo sujeito humano"36. Então, uma ação crítica transformadora é possível, desde que guiada pelos princípios éticos-

\footnotetext{
${ }^{32}$ Ibidem, p. 539.

${ }^{33}$ Ibidem, p. 541.

${ }^{34}$ MARX, op. cit., p. 103.

${ }^{35}$ DUSSEL, op. cit., p. 541.

${ }^{36}$ Ibidem, loc. cit.
} 
críticos, eis que a não observância de uma bússola crítica importaria uma pragmática funcionalista ${ }^{37}$.

Um Direito Crítico, portanto, serve de instrumento de acúmulo para a emancipação, embora se saiba que uma efetiva transformação exija uma ruptura estrutural e, por decorrência, com seu sistema formal de regulação - o direito. Um Direito Crítico deve-se espelhar na leitura revolucionária sobre a ação institucional sindical e parlamentar no sentido de valer-se dela sem imaginar que sua estratégia final ali se realizará. Trata-se de explorar as possibilidades insurgentes do sistema até seus limites, ou seja, o direito serve a uma ética da libertação enquanto tática de ação, considerada como instrumental dentre outras atuações e não como a medida central.

O Direito mostra-se como uma totalidade de pretensões de grupos sociais: uns que impõe através da dominação o Direito-Regulação; outros que lutam pela libertação fundados em um Direito-Emancipação. Deste modo, pode-se manejar um Direito Crítico a serviço da categoria de Dussel de transformação social.

\section{A HERMENÊUTICA FILOSÓFICA}

Na direção transformadora, o Direito Alternativo afirmou-se no Brasil como a principal prática de um direito crítico na década de 1990-2000. Pode-se visualizar três frentes do direito alternativo, conforme lição de Amilton Bueno (1992). A primeira corresponde ao uso alternativo do direito que é a utilização, via interpretação diferenciada das contradições, ambigüidades e lacunas do direito legislado numa ótica democratizante. A segunda é o positivismo de combate, entendido como o uso e reconhecimento do direito positivo como arma de combate, como luta para efetivação concreta dos direitos existentes que não são aplicados. A terceira é o direito alternativo em sentido estrito, assemelhado ao pluralismo jurídico, um direito paralelo, emergente,

\footnotetext{
${ }^{37}$ Ibidem, loc. cit.
} 


\section{As ALTERNATIVAS JURÍDICAS PARA UMA ÉTICA DA LIBERTAÇão: DO DIREITO \\ ALTERNATIVO A UMA HERMENÊUTICA FILOSÓFICA CRÍTICA}

insurgente, achado na rua, não-oficial, que coexiste com aquele emergente do Estado, ou seja, um direito vivo, que está em atuante formação/transformação.

Contudo, muitas críticas foram voltadas contra esse alternativismo, inclusive provenientes de visões progressistas e críticas do direito. Não se cuida de enfrentar as críticas preconceituosas jogadas maliciosamente pelos celibatos do positivismoformalista, muitas tolas e rasas porque baseadas em leituras de orelhas dos livros alternativistas. Cumpre lidar com a crítica lingüístico e política formulada por Luis Alberto Warat.

Warat $^{38}$ descreve que o desencanto com a forma de crítica jurídica alternativista no Brasil decorreu de seu estado "melancólico", por ser uma cópia "tardia" de prática européia e por um marxismo mecânico ou dogmático. Através da análise psicanalítica, o autor visualiza uma grande melancolia na afirmação do "uso alternativo do direito", que impõe-se sem fundamentação teórica, utilizando-se de elementos emocionais para, inclusive, porta-se com intolerância(absolutista e totalitário) com outro que não lhe aceita.

Os alternativistas tardios não enxergam, segundo Warat, no Estado Democrático de Direito um espaço de atuação para seus anseios. Não percebendo que o Estado de Direito é gerido por uma governabilidade correlacionada com as "condições democráticas de existência". O uso alternativo serviu a um contexto histórico do Estado ditatorial, não mais cabendo no atual momento histórico do Estado de Direito. Sua utilização alternativa significava a opção socialista, hoje descabida pelo fracasso deste sistema de governo. Defender o uso alternativo na atualidade resultaria no "capitalismo real de livre mercado". O Estado de Direito pode ser utilizado a partir da criatividade:

tem o sentido de uma história por fazer, que se irá fazendo num processo de auto determinação e de auto-constituição coletiva das regras que os limitem. Criativos enquanto

\footnotetext{
${ }^{38}$ WARAT, Luis Alberto. Introdução geral ao direito: o direito não estudado pela teoria jurídica moderna. Florianópolis: Fabris, 1997.
} 
atores ativos da realidade que vão constituindo. Nesta direção o criativo expressaria a tendência de valorar e racionalizar o real para legitimá-lo. Criação que toma como ponte a ética e a razão para que o homem construa a cidade e seja formado por ela em sua identidade e cidadania. Criatividade é constituição de cidadania no repúdio dos iluminados ${ }^{39}$.

Luciano Oliveira ${ }^{40}$ também aponta algumas críticas ao Direito Alternativo. Aduz que o anti-legalismo do Direito Alternativo não pode operar contra as conquistas e avanços dentro do próprio ordenamento jurídico, como garantias individuais do Estado Democrático de Direito (como ampla defesa, contraditório), bem como poderia significar a legitimação de práticas pluralistas autoritárias ou violentas, fundadas na delinquiência ou na força.

Ainda que algumas dessas críticas não se revelem justas ou consistentes, é preciso entender superado historicamente o movimento do Direito Alternativo, embora seja preciso enaltecer sua valiosa contribuição histórica para a crítica jurídica nacional. Trata-se precisamente de reconhecer inconsistente no momento presente o uso alternativo do direito e certos estereótipos que acompanhavam seus defensores. No entanto, acolhe-se a utilidade do positivismo de combate e a legitimidade das práticas pluralistas.

Qualificar como superado o uso alternativo do direito não prejudica a ética da libertação, porque tem ganhado expressão uma outra perspectiva jurídica com o potencial de substituí-lo, atingindo a mesma finalidade, mas com uma fundamentação epistemológica mais consistente. Cuida-se da hermenêutica filosófica que inaugura uma postura de atribuir a interpretação um papel criativo, notadamente a partir da contribuição de Hans-George Gadamer.

A hermenêutica em Gadamer passa de método para filosofia. Os métodos de interpretação não são mais o foco central da hermenêutica, mas sim a própria possibilidade de compreensão. "Y ahora se trataba de transformar esa técnica em um

\footnotetext{
${ }^{39}$ Ibidem, loc. cit.
}

${ }^{40}$ OLIVEIRA, Luciano. Ilegalidade e direito alternativo: notas para evitar alguns equívocos. In: SOUTO, Cláudio; FALCÃO, Joaquim (orgs.). Sociologia e direito: textos básicos para a disciplina de sociologia jurídica. São Paulo: Pioneira Thomson, 2002. 


\section{AS Alternativas JURídicas PARA UMA ÉTICA dA LIBERTAÇÃo: DO DIREITO \\ ALTERNATIVO A UMA HERMENÊUTICA FILOSÓFICA CRÍTICA}

sistema filosófico que dé razón delas estructutes irrenunciables em toda comprensión" ${ }^{41}$. Trata-se da hermenêutica filosófica, que teve seu princípio em Martin Heidegger. Heidegger instaura uma grande viragem na compreensão hermenêutica, quando busca a revelação do texto, ou seja, quando adentra nele para refazê-lo. Essa reconstrução interpretativa não significa que a compreensão hermenêutica propõe-se a entender o texto melhor que seu autor, ao contrário, sendo a compreensão obra do ser será necessariamente diferente, isto é, a interpretação não é reprodutiva e sim produtiva.

O pilar desta viragem foi a ruptura de Heidegger com a metafísica, com a filosofia da consciência de Kant a Hegel. A hermenêutica filosófica assevera que a possibilidade de compreensão dos textos, e da própria vida, é assentada no próprio ser, e não na consciência. Neste novo paradigma, não há mais a distância entre sujeito e objeto (o sujeito que apreende no intelecto o objeto), mas sim a relação sujeito-sujeito, que transpõe à compreensão para o perfil da reconstrução. Em outras palavras, compreender é ser (novamente e diferente) o que está a se compreender. A hermenêutica filosófica gadameriana dirigi-se à perquirição da compreensão, isto é, não se pauta na discussão das técnicas interpretativas, para focar seus esforços numa questão preliminar a tais técnicas, qual seja: o que é a compreensão?

Gadamer, auto-proclamado discípulo de Heidegger, desenvolve sua contribuição à hermenêutica filosófica numa perspectiva complementar à heideggeriana. Tratou, inicialmente, de dirigir sua crítica ao pensamento cartesiano que condicionava à verdade à adequação ao método. Sua obra, Verdade e Método, serviu a tal crítica, valendo-se de grande ironia no título. Tinha como objetivo central:

A tese de meu livro é, pois, que o momento histórico-efeitual é e permanece efetivo e atuante em toda a compreensão da tradição, mesmo onde a metodologia das modernas ciências históricas ganhou espaço, e transforma em "objeto" aquilo que veio a ser historicamente, o que foi transmitido historicamente, que se deve "estabelecer" como um dado experimental -

41 FERNÁNDEZ-LARGO, Antonio Osuna. Hermenéutica jurídica: em torno a la hermenêutica de Hans-Georg Gadamer. Valladolid: Universidad, 1992, p. 50. 
como se a tradição fosse estranha e, humanamente falando, incompreensível enquanto objeto da física ${ }^{42}$.

Verifica-se, dessa forma, na hermenêutica filosófica a historicidade. Todo intérprete já conserva consigo alguns juízos prévios que conformam uma intenção preliminar na interpretação. No momento da formulação da pré-compreensão, e também da compreensão, o elemento histórico atua fazendo com que esta hermenêutica seja perpassada pela historicidade.

A descoberta da estrutura prévia da compreensão (pré-compreensão) de Heidegger é fundamental e imprescindível para a hermenêutica filosófica aventada. Em consideração da existência mundana do sujeito, este carregará consigo sua história, opções, ideologias, medos e opiniões que constituem sua pré-compreensão. A estrutura prévia da compreensão atua com manifesta interferência na hermenêutica, pois realiza os recortes possíveis de interpretação ou mesmo confere um sentido próprio e distinto de outros intérpretes, concatenado com a o pré-juízo.

Gadamer considera que a interpretação é um ato de projetar, que começa por conceitos prévios que serão, a posteriori, substituídos por mais adequados, fazendo movimento circular: preconceito - texto - conceito - sentido.

[Assim], O movimento da compreensão vai constantemente do todo para a parte e desta para o todo. A tarefa é ir ampliando a unidade do sentido compreendido em círculos concêntricos. O critério correspondente para a justeza da compreensão é sempre a concordância de cada particularidade com o todo. Se não houver tal concordância, significa que a compreensão malogrou $^{43}$.

$\mathrm{Na}$ virada ontológica da hermenêutica filosófica, a linguagem exsurge como a centralidade da compreensão ou, ainda, como a garantia da possibilidade de compreensão. Mais que isso, o próprio ser é linguagem e, dessa maneira, só na

${ }^{42}$ GADAMER, Hans-Georg. Verdade e método. 7. ed.. Trad. de Flávio Paulo Meurer. Petrópolis: Vozes, 2005, p. 20.

${ }^{43}$ Ibidem, p. 386. 


\section{AS Alternativas JURídicas PARA UMA ÉTICA dA LIBERTAÇÃo: DO DIREITO \\ ALTERNATIVO A UMA HERMENÊUTICA FILOSÓFICA CRÍTICA}

linguagem (não mais na consciência) que o ser se manifesta.

É a afirmativa do paradigma da filosofia da linguagem, que supera, segundo seus defensores, a filosofia da consciência que atribuía um papel instrumental e sem destaque à linguagem. "A linguagem não é uma terceira coisa que se interpõe entre o sujeito e objeto, ou seja, na concepção hermenêutica de Gadamer não há espaço para a dicotômica relação epistemológica sujeito-objeto" ${ }^{44}$.

Pode-se dizer que a hermenêutica pressupõe um compromisso com o diálogo, que não significa neutralidade ou mero acolhimento automático das idéias do texto, mas apenas está aberto para recepcionar novas contribuições.

Aquele que quer compreender não pode se entregar de antemão ao arbítrio de suas próprias opiniões prévias, ignorando a opinião do texto da maneira mais obstinada e conseqüente possível. Em princípio, quem quer compreender um texto deve estar disposto a deixar que este lhe diga alguma coisa ${ }^{45}$.

A abertura ao texto é, efetivamente, uma postura dialógica de intercâmbio entre o texto e o intérprete. Com isso, a hermenêutica foge da tentativa de interpretação silenciosa e anti-dialógica dos textos, que foi sustentada pelos dogmatismos intrínsecos às pretensões (pretensamente) neutras de explicações analíticas. Então, a relação intérprete e texto, isto é, a compreensão é uma relação dialética, no contexto da filosofia da linguagem.

\section{UMA HERMENÊUTICA CRÍTICA}

Mesmo considerando o papel criativo/produtivo da interpretação, constata-se

\footnotetext{
${ }^{44}$ STRECK, op. cit., p. 202.

${ }^{45}$ GADAMER, op. cit., p. 358.
} 
uma ausência de crítica à ideologia em Gadamer, notadamente no pôr-se de acordo com a tradição. Nesta postura, desconsidera-se a circunstância de que tanto a tradição e a interpretação são engendradas numa historicidade tangenciada pelos conflitos econômicos e sociais. Não se percebe a crítica na hermenêutica filosófica, como pontua Ernildo Stein: "A universalidade da crítica parte das condições históricas materiais e afirma que a universalidade que não é crítica [hermenêutica filosófica] não percebe as condições a partir das quais ela é gerada" ${ }^{46}$.

Anote-se que Gadamer manifesta uma postura tradicionalista, pois não submete à reflexão crítica à autoridade e à tradição. Apesar de ser consideravelmente importante o entendimento da tradição (momento histórico) e autoridade para a tarefa hermenêutica, não se pode estipular que o acordo entre o intérprete e o texto, resultante dos diálogos destes, confirme-se como uma mera e acrítica aceitação do sentido do texto. Vale transcrever a crítica de D. Böhler à inexistência de crítica em Gadamer quando tem vinculado à idéia de compreensão com o "acordo" do intérprete com o texto:

Podemos nos comportar dialogicamente para com o sentido expresso, sem deixar que esta fique valendo no final [...] Compreender a si mesmo como destinatário da pretensão não significa ter de aceitar a pretensão, mas sim, decerto, tomá-la a sério ${ }^{47}$.

Quando Gadamer enaltece a tradição e a autoridade possibilita que lhe seja atribuído o qualificativo de conservador. "Certamente, o apelo idealista e vago à tradição opera, em Gadamer, como um ingrediente conservador, embora ele timbre em distinguir em preconceitos legítimos e ilegítimos" ${ }^{48}$. A falta de crítica à tradição impede que a hermenêutica gadameriana consiga se prevenir contra a alienação. Se a

${ }^{46}$ STEIN, Ernildo. Dialética e hermenêutica: uma controvérsia sobre o método em filosofia. In: HABERMAS, Jürgen. Dialética e hermenêutica. Trad. Álvaro Valls. Porto Alegre: L\&PM, 1987, p. 100 ,

${ }^{47}$ Apud HABERMAS, Jürgen. Dialética e hermenêutica. Trad. Álvaro Valls. Porto Alegre: L\&PM, 1987, p. 95.

${ }^{48}$ LYRA FILHO, Robert. Porque estudar direito hoje? 4. ed. Brasília: UnB, 1993, p. 72. 


\section{AS Alternativas JURÍdicas PARA UMA ÉTICA DA LibERTAÇÃo: DO DIREITO ALTERNATIVO A UMA HERMENÊUTICA FILOSÓFICA CRÍTICA}

compreensão for, rigorosamente, o pôr-se de acordo com a tradição, seria, então, mera assimilação de sentido na perspectiva da conservação, eis que não perceberia como este sentido foi construído ou a quem serve. Ter-se-ia uma hermenêutica alienada.

Neste espectro conservador, não se vê na hermenêutica filosófica espaço para uma ética libertadora, pois mesmo a tradição (que advêm também das coletividades) é aceita acriticamente. O discurso hermenêutico omite-se quanto aos sujeitos coletivos e suas relações com a produção do conhecimento. $\mathrm{STRECK}^{49}$, entretanto, não concorda com esta feição conservadora, pois entende que a hermenêutica gadameriana é crítica, eis que a observância à tradição seria somente no sentido de receptividade e não determinação. Do ângulo materialista, critica-se esta omissão acerca dos fenômenos coletivos e o foco no ser (subjetiva e individualmente considerado), eis que representa a prevalência da parte, em detrimento das relações entre parte (ser) e todo (coletividades). Talvez, seja necessário enxergar uma outra face da pertença em Gadamer, qual seja: a pertença à coletividade.

Este afastamento (ausência de crítica e desconsideração dos fenômenos políticos) tem, segundo uma visão materialista, imputado à hermenêutica filosófica uma função conservadora. Reconhece-se sua capacidade de compreensão dos sentidos, critica-se a falta de motivação transformadora.

Enquanto a hermenêutica busca a compreensão, o método dialético introduz o princípio do conflito e da contradição como constitutivos da realidade e, portanto, essenciais para sua compreensão. A razão e a pesquisa, mais que do que interpretar e compreender a realidade social, podem exercitar a crítica e superar pré-juízos. Assim, a dialética marxista considera que as relações sócio-históricas (dinâmicas, antagônicas e contraditórias) entre classes, grupos e culturas são o fundamento da comunicação humana e como nada se constrói fora da história, qualquer texto (em sentido amplo) precisa ser lido em função do contexto no qual foi produzido, porque só poderá ser entendido na totalidade dinâmica das relações sociais de produção e reprodução nos quais se insere ${ }^{50}$.

\footnotetext{
${ }^{49}$ STRECK, op. cit.

50 AZEVEDO Marco Antônio de. Informação e interpretação: uma leitura teórico$<$ http://www.eci.ufmg.br/pcionline/include/getdoc.php?id=243\&article=71\&mode=pdf $>$ Acesso em: 5
} metodológica. jul. 2006, p. 132. 
Além destas críticas, há uma longa distância entre a hermenêutica filosófica e uma ética libertadora no que tange ao papel da linguagem. No viés acrítico e conservador, o giro lingüístico conduz a uma defesa da linguagem que englobaria em si todo o conhecimento e o próprio (representação do) homem. Tamanho poder à linguagem, mais uma vez, mascararia as relações de poder que interferem na produção e na possibilidade de comunicação. Terminaria, pois, supervalorizando à lingüística e esquecendo da semiologia do poder.

Ademais, a hermenêutica filosófica centrando-se na linguagem, como única possibilidade da compreensão, termina por desconsiderar as deturpações da linguagem. Problemas individuais, tratados pela psicanálise, ou fenômenos coletivos, advindos dos condicionamentos econômicos e sociais, provocam distorções na comunicação. Ignora principalmente que os espaços de manifestação lingüística e de discursividade são diretamente relacionados com as questões materiais cotidianas, que os que se alienam no trabalho ou não conseguem dominar a fala por uma diversidade de questões ou pouco podem elaboram um discurso convincente para os que têm capacidade lingüística. Stein comenta:

A experiência hermenêutica só não seria suspeita se ela não acontecesse no seio da linguagem sistematicamente perturbada. Mas como a comunicação sistematicamente perturbada é um aspecto da sociedade no qual os homens vivem na alienação, e já que a alienação nasce da dominação de homens sobre homens, a comunicação livre de dominação converte-se em idéia regulativa da crítica das ideologias ${ }^{51}$.

Numa aproximação dialética entre a hermenêutica filosófica e um Direito Crítico, é possível insinuar uma ou várias hermenêuticas críticas. Alguns teóricos marxistas agregaram a psicanálise à hermenêutica filosófica. Foram Hans Jörg Sandkühler e Alfred Lorenzer. Inicialmente reconhecem e enfatizam a subjetividade, componente que não recebeu a atenção de Marx e Engels. Entretanto, criticam a

\footnotetext{
${ }^{51}$ STEIN, op. cit., p. 126.
} 


\section{AS Alternativas JURídicas PARA UMA ÉTICA dA LIBERTAÇÃo: DO DIREITO \\ ALTERNATIVO A UMA HERMENÊUTICA FILOSÓFICA CRÍTICA}

hermenêutica filosófica pela exarcebação do ser, que conduz ao individualismo e a desconsideração dos fatores econômicos e políticos:

Para a hermenêutica crítica, a autoconcepção idealista de uma troca de sentido sem quaisquer impedimentos é, quando muito, uma antecipação de um verdadeiro estado de inexistência humana a concretizar; a pressuposição de que este estado existe já, subjacente às metodologias objectivo-idealista, levanta desconfianças ideológicas ${ }^{52}$.

Para Lorenzer, o realce marxista para a subjetividade deve-se dar pela psicanálise, entendida como teoria crítica do sujeito ${ }^{53}$. O autor acredita que a subjetividade resulta de um processo de socialização prática-dialético, isto porque é a confrontação entre o interior (subjetivo) e o exterior histórico (objetivo). "As estruturas subjectivas de um indivíduo, que são o objecto da psicanálise, não são, conseqüentemente, algo determinado ahistoricamente, mas antes um resultado de um processo histórico" ${ }^{25}$. Trata-se da confluência de Marx e Freud que reclama uma subjetização do marxismo e uma crítica histórica-política para a psicanálise.

É, por conseguinte, um requisito prévio de uma relação proveitosa entre a psicanálise e o materialismo histórico, que a primeira abandone a sua abordagem subjectivista que vem buscar à sua totalidade histórica e rompa o véu da teoria reificada da personalidade, através da categoria da forma de interação. A teorização marxista teria, simultaneamente, de abandonar as tendências objectivistas surgidas nas correntes actuais ${ }^{55}$.

Destoante de Lorenzer, Sandkühler discorda da junção psicanálise e materialista, alegando a incompatibilidade entre tais teorias. Sua razão ${ }^{56}$ indica que a concepção da hermenêutica filosófica, enquanto ontologia (epistemologia) afirmadora do existencialismo individual, exclui categorias essenciais ao marxismo, como a

\footnotetext{
${ }^{52}$ BLEICHER, Josef. Hermenêutica contemporânea. Lisboa: Edições 70, 2002, p. 234.

${ }^{53}$ Ibidem, p. 235.

${ }^{54}$ Ibidem, p. 237.

55 Ibidem, p. 239.

${ }^{56}$ Ibidem, p. 242.
} 
Revista Eletrônica do CEJUR, Curitiba-PR, a. 2, v. 1, n. 3, ago./dez. 2008

totalidade. Assim, Sandkühler refaz sua concepção de hermenêutica materialista, entendo-a como método (técnica interpretativa), e não mais enquanto teoria geral da compreensão. Dessa forma, a hermenêutica materialista é um sub-sistema da dialética materialista, funcionando da seguinte forma:

\begin{abstract}
A hermenêutica materialista procura a reflexão intelectual da história actual, encontrada nas fontes e textos históricos, e interpreta-os reconstruindo o seu processo de criação. Por conseguinte, deixou de caber à hermenêutica repensar o que tinha sido antes; a hermenêutica materialista está consciente da não-identidade do objecto e do sujeito; parte da história, como pruduto intelectualm a fim de ficar a conhecer verdadeiramente os processos históricos, e tenta distinguir os factores subjacentes à discrepância entre a existencial actual e o seu reflexo nas mentes dos agentes humanos ${ }^{57}$.
\end{abstract}

Mesmo envolto de distanciamentos e críticas, já se pode falar em uma hermenêutica-dialética. Registre-se a existência de estudos acerca deste diálogo hermenêutico-dialético no âmbito das ciências da saúde que, inclusive, já tem esboçado uma função para uma hermenêutica dialética, que, além da análise crítica, seria:

Uma análise hermenêutico-dialética busca, portanto, apreender a prática social empírica dos indivíduos em sociedade em seu movimento contraditório. Levando em conta que vivem em uma determinada realidade, pertencem a classes, grupos e segmentos diferentes, são condicionados por tal momento histórico e, por isso, podem ter, simultaneamente, interesses coletivos que os unem e interesses particulares que os distinguem e os contrapõem. Sendo assim, a orientação dialética de qualquer análise diz que é fundamental realizar a crítica das idéias expostas nos produtos sociais (discursos, textos, instituições, monumentos) buscando, na sua especificidade histórica, a cumplicidade com seu tempo e nas diferenciações internas, sua contribuição à vida, ao conhecimento e às transformações ${ }^{58}$.

\footnotetext{
${ }^{57}$ Ibidem, loc. cit.

${ }^{58}$ AZEVEDO, op. cit., p. 132.
} 


\section{As Alternativas JURídicas PARA UMA ÉTICA dA LIBERTAÇÃo: DO DIREITO \\ ALTERNATIVO A UMA HERMENÊUTICA FILOSÓFICA CRÍTICA}

\section{8 (IN)CONCLUSÕES}

A par de tudo isso, arremata-se alguns pontos conclusivos, como sintetizadores das questões levantadas neste ensaio. Ou melhor, são pontos hipotéticos que carecem de desenvolvimento e crítica e, por isso, mais inconclusivos do que prontos e finalizados. Trata-se da conhecida relação dialética conclusão-inconclusão ou afirmação-negação.

Se uma ética libertadora exige todos os esforços para a contenção e transformação da realidade de exploração e exclusão social, a seara jurídica não pode ser um palco a se furtar desse intento transformador. Isto porque "A função do direito [...] é a de possibilitar o exercício efetivo dos direitos sonegados, bem como a incorporação de novos direitos" ${ }^{59}$. Em síntese, de conceber e praticar um Direito Crítico.

Contudo, a ação transformadora não crê que sua pretensão se realizará radicalmente no plano do instituído e da ordem jurídica. A lição de Rosa Luxemburgo é paradigmática, porquanto relembra o equívoco do reformismo que relegou o horizonte revolucionário em troca de concessões temporárias - eis o Welfare State cedeu ao Neoliberalismo - do capitalismo. Em outras palavras, um direito realmente crítico exige uma nova estrutura social, não se contentando com mais positivações de direitos ou no reclame pela efetividade dos já existentes. A ética libertadora almeja uma convicção jurídica que prossiga até limite máximo das concessões capitalistas para demonstrar dialeticamente a injustiça estrutural que alicerça a sociedade. Reivindica-se direitos que se levados a cabo transformariam a dinâmica capitalista e, por isto, a ordem vigente não os realiza na sua inteireza. Afirmar-se para negar e, assim, caminhar para a transformação!

Nesse caminho, uma hermenêutica crítica - consistente substituta do Direito Alternativo - é factível, desde que proveniente de confrontação dialética das

\footnotetext{
${ }^{59}$ LUDWIG, op. cit., p. 222.
} 
experiências interpretativas ou de uma fusão de horizontes na práxis transformadora. As diferenças entre uma ética libertadora e a hermenêutica filosófica não enfraquecem a possibilidade deste diálogo, apenas reclamam um maior desenvolvimento das proximidades e superação das distâncias, que caberá à historicidade. Por enquanto, resta enfatizar, como maior contribuição deste diálogo, uma interpretação produtiva a serviço da transformação.

\section{REFERÊNCIAS}

ANDRADE, Carlos Drummond. A rosa do povo. 25. ed. Rio de Janeiro: Record, 2002.

AZEVEDO Marco Antônio de. Informação e interpretação: uma leitura teóricometodológica. In: $<$ http://www.eci.ufmg.br/pcionline/include/getdoc.php?id=243\&article=71\&mode=pd f> Acesso em: 5 jul. 2006.

CARVALHO, Amílton Bueno de. Magistratura e direito alternativo. São Paulo: Acadêmica, 1992.

BLEICHER, Josef. Hermenêutica contemporânea. Lisboa: Edições 70, 2002.

DUSSEL, Enrique. Ética da libertação na idade da globalização e da exclusão. Trad. Ephraim Ferreira Alves, Jaime A Clasen, Lúcia M.E. Orth. Petrópolis: Vozes, 2007.

GADAMER, Hans-Georg. Verdade e método. 7. ed.. Trad. de Flávio Paulo Meurer. Petrópolis: Vozes, 2005.

IPEA. Previdência reduziu em 44\% o número de miseráveis, diz IPEA. In: <http://www.ipea.gov.br/003/00301009.jsp?ttCD_CHAVE=2498> Acesso em: 27 fev. 2008.

FERNÁNDEZ-LARGO, Antonio Osuna. Hermenéutica jurídica: em torno a la hermenêutica de Hans-Georg Gadamer. Valladolid: Universidad, 1992.

HABERMAS, Jürgen. Dialética e hermenêutica. Trad. Álvaro Valls. Porto Alegre: L\&PM, 1987.

LUDWIG, Celso. Para uma filosofia jurídica da libertação: paradigmas da filosofia da libertação e direito alternativo. Florianópolis: Conceito, 2006. 


\section{As ALTERNATIVAS JURÍDICAS PARA UMA ÉTICA DA LIBERTAÇão: DO DIREITO \\ ALTERNATIVO A UMA HERMENÊUTICA FILOSÓFICA CRÍTICA}

LUXEMBURGO, Rosa. Reforma ou revolução. Trad. Livio Xavier. São Paulo: Expressão Popular, 1999.

LYRA FILHO, Roberto. O que é direito. Rio de Janeiro: Brasiliense, 1982.

. Para um direito sem dogmas. Porto Alegre: Fabris, 1984.

. Porque estudar direito hoje? 4. ed. Brasília: UnB, 1993. (Série o Direito achado na rua).

MACHADO NETO, A. L. Compêndio de introdução à ciência do direito. 6. ed. São Paulo: Saraiva, 1988.

MARQUES NETO, Agostinho Ramalho. A ciência do direito: conceito, objeto e método. São Paulo: Forense, 2000.

MARX, Karl; ENGELS, Friedrich. Ideologia alemã. São Paulo: Martins Fontes, 1998. (Coleção Clássicos Filosofia/Ciências Sociais).

OLIVEIRA, Luciano. Ilegalidade e direito alternativo: notas para evitar alguns equívocos. In: SOUTO, Cláudio; FALCÃO, Joaquim (orgs.). Sociologia e direito: textos básicos para a disciplina de sociologia jurídica. São Paulo: Pioneira Thomson, 2002.

OLIVEIRA, Murilo Carvalho Sampaio Oliveira. Crise do direito do trabalho. Revista LTR, v. 70, p. 998-1007, 2006.

- Diálogos hermenêuticos: a hermenêutica gadameriana e a dialética crítica. 2006 - Monografia da disciplina de Hermenêutica do Mestrado em Direito da UFBA.

. Serviço de apoio jurídico - SAJU: a práxis de um direito crítico. - Monografia de Graduação em Direito. Universidade Federal da Bahia, UFBA, 2003. ONU in <http://www.un.org > Acesso em: 26 fev. 2008.

PALMER, Richard E. Hermenêutica. Lisboa: Edições 70, 1996.

POCHMANN, Márcio. Razões da desigualdade no Brasil. In: $<$ http://www.vermelho.org.br/diario/2005/1002/1002_pochmann.asp> Acesso em: 27 fev. 2008.

REALE, Giovanni; ANTISERI, Dario. História da filosofia: de Nietzsche à Escola de Frankfurt. Trad. Ivo Storniolo. São Paulo: Paulus, 2006. (Coleção História da Filosofia $6)$.

SANTOS, Boaventura de Souza. Porqué no te callas?. Jornal da UnB - Constituição e Democracia, dez. 2007.

Porquê pensar? Revista da AATR - Associação de Advogados de Trabalhadores 
Rurais, Salvador, a. 3, n. 3, 2005.

A crítica da razão indolente: contra o desperdício da experiência. 3. ed. São Paulo: Cortez, 2001.

SOUZA JR, José Geraldo. Para uma crítica da eficácia do direito. Porto Alegre: Fabris, 1984.

STEIN, Ernildo. Dialética e hermenêutica: uma controvérsia sobre o método em filosofia. In: HABERMAS, Jürgen. Dialética e hermenêutica. Trad. Álvaro Valls. Porto Alegre: L\&PM, 1987.

STRECK, Lênio. Hermenêutica jurídica e $(m)$ crise: uma exploração hermenêutica da construção do direito. 6. ed. Porto Alegre: Livraria do Advogado, 2005.

WARAT, Luis Alberto. Introdução geral ao direito: o direito não estudado pela teoria jurídica moderna. Florianópolis: Fabris, 1997.

WOLKMER, Antônio Carlos. Introdução ao pensamento jurídico crítico. São Paulo: Acadêmica, 2000. 